\title{
The pericyte progenitors and the pericytes are the ancestors of the inner ear structures
}

Running title: The inner ear structures are pericyte progeny?

\author{
M. S. Davidoff
}

University Medical Center Hamburg-Eppendorf, Hamburg, Germany

\begin{abstract}
This short scientific overview concerns the morpho-functional comparison between the omnipresent pericytes and the pericytes of the inner ear and, besides some characteristic features of the last, provides evidence that the otic pericytes are authentic part of the omnipresent pericyte (adult stem cell) population of the vertebrate organism. In the present review we offer evidences for a new hypothesis that the pericyte progenitors and the pericytes, as pluripotent epiblast derivatives, are the ancestors of the supporting and hair cells of the Corti organ, the cells of the vestibular (balance) organ and the neural elements of the inner ear in norm and experiment. The most important evidences for this statement provide results concerning: 1. the origin of the inner ear vasculature; 2 . the close relationships of the pericytes with the microvasculature of the inner ear (periendothelial location in microvascular niches); 3.their importance for the blood-labyrinth barrier; 4. the events that accompany the origin of the inner ear sensory epithelia; 5 . the authentic stem cell qualities of the pericytes allowing the production of cells and tissues characteristic for the three embryonal germ layers: ectoderm, mesoderm and endoderm (during embryogenesis, in the adult organisms and at experimental and pathological conditions), as well as 6 . the remarkable pericyte plasticity and their involvement in the immune system.
\end{abstract}

Key words: Pericytes, inner ear, cochlea, Corti organ, adult stem cells

\section{List of Abbreviations:}

AGM - Aorta - Gonad - Mesonephros $\alpha$-SMA - alpha Smooth Muscle Actin BBB - Blood-Brain-Barrier

BLB - Blood-Labyrinth-Barrier

$\mathrm{BM}$ - Bone merrow

BrdU - Bromo-deoxyuridine

bFGF - beta Fibroblast growth factor

$\mathrm{CD}$ - Cluster of differentiation

$\mathrm{CNS}-$ Central nervous system

$\mathrm{CO}-$ Corti organ

dpc - days postcoitus

E - Embryonic day

EC - Endothelial cells

ESC - Embryonic stem cells

EPI - Epiblast

FBB - Fluid-Blood-Barrier

GER - Grater Epithelial Ridge

GFAP - Glial fibrillary acidic protein

GTPase - Guanosine -Triphosphatase

HIF - Hypoxya inducible factor

HSCs - Hematopoietic stem cells

ICM - Inner cell mass

LER - lower epithelial ridge

LTR - Long term repopulating

HSCs - Hematopoietic stem cells

LGR5 or GPR49 - Leucine-rich repeat-containing G-protein coupled receptor

LTR - Long-term repopulating capability

MCAM (also CD146) - Melanoma cell adhesion molecule

MMS - Monocyte-Macrophage-System

MSCs - Mesodermal stromal cells

NCAM 1 (also CD56) - Neural cell adhesion molecule 1

NG2 - Neuron-glial antigen 2

NPB - Neural plate border

OEPD - Otic - epibranchial progenitor domain

PDGFR $\alpha$ and $Я$ - Platelet-derived growth factor alpha and beta

PCs - Pericytes

PGCs - Primordial (primitive) germ cells

PPR - Pre-placodal region

$\mathrm{PVM} / \mathrm{MS}$ - Perivasculkar resident macrophage-like melanocytes 
RGS-5 - Regulator of G protein signaling - 5

SOX2 - SOX2 (SRY(sex determining region Y) - box 2

TPCs - Transit amplifying cells

VEGF - Vascular endothelial growth factor

W - Weak

UCB - Umbilical cord blood

\section{Definition of pericytes}

The pericytes are cells that are integral part of the microvasculature (precapillaries, capillaries, postcapillaries) of tissues and organs. They have (1, 2) within a space called true microvascular niche where they remain the whole life as resting adult pluripotent stem cell population for tissue/organ generation, maintenance, repair, and regeneration of the structures in the adult vertebrate organism (3 - 9). For the immunohistochemical identification of the pericytes a number of bioactive markers (transcription factors) that they express is used because there is no a typical marker that identifies only the pericytes. The most frequently used factors are: Cluster of differentiation 146 (CD146; also known as Melanoma cell adhesion molecule; MCAM), Cluster of differentiation 56 (CD56; also known as Neural cell adhesion molecule - NCAM 1), Platelet-derived growth factor receptor beta and -alpha (PDGFR- $Я$ and $-\alpha$ ); alpha-smooth muscle actin ( $\alpha$-SMA); tropomyosin; desmin; Nestin (predominantly during the activation and proliferation of the pericytes), Neuron-glial antigen 2 (NG2, a chondroitin sulfate proteoglycan); Aminopeptidase A and -N; Membrane glycoprotein Thy-1 (CD90); regulator of $\mathrm{G}$ protein signaling 5 (RGS-5): a GTPase-activating protein; clas III beta tubulin; pericyte-associated cell surface antigen (3G5) (1, $4,5,8$ - 16).

\section{The pericytes are the adult stem cells of the vertebrate organism, inclusive the inner ear}

With minor exceptions (17, but see 18$)$, the pericytes have been increasingly defined as the pluripotent stem cell type of the adult mammalian body (see 8, 9, 19, 20). They are an omnipresent cell population (pan-organ stem cells; 9, 21). This is related to the fact that the pericytes represent the only pluripotent adult cell population in the vertebrates that are able to produce structures characteristic for the tree embryonal germ layers (ectoderm, mesoderm and endoderm) which explains their extraordinary high plasticity. All other stem-like cells in an organism (inclusive the Mesenchymal Stem Cells - now renamed Mesodermal Stromal Cells - MSCs, see 9, for references; 12, 24-26; also tumor cells 124) represent pericyte progeny (TPCs: Transit amplifying cells that transdifferentiate to progenitor cells) with diminished potency, namely they are multipotent cells which differentiate, via intermediate forms, toward progenitors of numerous characteristic for an organ immature and mature cells. Their differentiation depends on the location, the stage of differentiation, the influences of the epigenetic (key intrinsic regulators) and the environmental factors. These events start to function very early in the embryogenesis with the early epiblast and the trophectoderm cells of the blastocyst $(22,23)$.

\section{Key moments of the embryogenesis of the sensory placodes and the inner ear}

The inner ear originates early in embryonic development with the generation of the sensory placodes. The cells of the sensory placodes are progeny of the epiblast, a cell cluster arising within the inner cell mass of the blastocyst (23). A part of the epiblast cells become committed toward definitive ectoderm and the neural plate (CNS). A second part generates the neural plate border (NPB) ectoderm or the pre-placodal region (PPR)(Fig 1)..

\section{Origin of the inner ear vasculature}

Normal blood supply to the cochlea is very important for establishing the endocochlear potential and sustaining production of endolymph $(2,27,28)$. The inner ear pericytes are also structural and functional components of the microvasculature.

The inner ear vasculature is part of the head resp. brain vasculature that originates very early during embryogenesis. It is important to note that the cardiovascular system is the first functioning system in the vertebrate embryogenesis (29 - 31). The origin of the vascular system starts with the development of extraembryonic angioblast cells (32) which in chick are generated from pluripotent epiblast and hypoblast bFGF-expressing cells of the pregastrula stages embryonic mesoderm $(33,34)$ that build the endothelial precursors. These cells assemble and generate a thin capillary network termed primary (perineural) capillary plexus $(35,36)$.

The new created endothelial cells migrate toward the progeny of the embryonic mesoderm, namely the paraaortic splanchnopleura and its derivative, 
the aorta-gonad-mesonephros (AGM) region, as well as the yolk sac where they generate blood islands that comprise vascular endothelial cells and hematopoietic stem cells (nucleated red blood cells) (30, 37 - 41; for the allantois see 42). Moreover, in E12.5 to E17.5 mouse embryos, strong expression of Rgs 5 in the arterial walls was observed by (43). Interestingly, the $\operatorname{Rgs} 5$-positive cells strongly resemble the pericytes which also produce plateletderived growth factor receptor (PDGFR)- $\beta$.

The inner ear receives its blood supply from the spiral modiolar artery (or cochlear artery, 44), a branch of the anterior inferior cerebellar artery whose branches generate three parallel networks (27). Thus, it became evident that the inner ear is richly supplied with vessel networks some of which contain a large number of pericytes, which show clear structural and biochemical plasticity $(2,27$, 45- 47). The main capillary networks in the inner ear are the vascular plexuses of the Stria vascularis and of the Spiral ligament in the cochlear lateral wall, followed by the plexus of the osseous spiral lamina (48). Using immunohistochemistry for the pericyte marker proteins: alpha-smooth muscle actin ( $\alpha$-SMA), desmin, Thy-1(CD90), tropomyosin, and neural-glial antigen (NG2), Shi et al (45) reported that pericytes were predominantly found in the capillary network of the cochlear lateral wall, with considerable morphological and biochemical heterogeneity across different types of microvessels. For example, pericytes on the vessels of the spiral ligament strongly express the gap junction protein connexin 40 as well as alpha-smooth muscle actin ( $\alpha$-SMA), tropomyosin, and desmin. In contrast, pericytes on the vessels of the stria vascularis show positivity for desmin, but not $\alpha$-SMA and tropomyosin $(2,45,49)$. These differences may reflect variations in the maturity of the pericytes under study connected with a process of differentiation from the arteriolar precapillary toward the postcapillary venule pericytes (11). In the last the pericytes are more differentiated and have lost their $\alpha$-SMA capacity. Functionally this may suggest that pericytes on spiral ligament vessels may have contractile properties, while those on the stria vascularis may not $(49,50)$. Recently Jiang et al (48) reported about changes in cochlear vascular density with ageing (s. 51). A similar event was observed in the vessel of the basilar membrane in the rat cochlea. The vessel of the basilar membrane under the organ of Corti is much larger during embryonic life, in comparison with the adult life, which allows the presumption that it may be important for the development and the regeneration of the organ of Corti $(28,52)$.

\section{The pericytes, the microvasculature and the neuro-vascular unit (NVU)}

As mentioned the pericytes are a structural component of the microvasculature. This is the first important definition feature. Montiel-Eulefi et al (53) found that embryonic (epiblast) stem cells derived from the inner cell mass of the rodent blastocyst (at $6-6.5 \mathrm{dpc}$ ) produce primordial germ cells and pericyte stem cells associated to the vessels endothelium in the yolk sac. As we will see below the growing vasculature is the structure that fulfills the broad dissemination of the pericytes in the whole mammalian organism during embryoand fetogenesis, adult angiogenesis as well as organ reparation/regeneration, and tumorigenesis (124)

There is close relationship between the vasculature and the innervation of an organ. Both operate as a neuro-vascular unit and influence each other $(49,50,54-57)$._Dore-Duffy (58) highlights that pericytes are highly complex regulatory cells that communicate with endothelial cells and other cells of the neurovascular unit (neurons, astrocytes, microglia, macrophages) by direct physical contact and through autocrine and paracrine signaling pathways $(55,56,59,60)$. Moreover, Shi $(27)$ inform that fibrocytes of the lateral cochlear wall resemble astrocytes and glial cells of the CNS. In this respect there is evidence that the pericytes are ancestors of both fibroblasts/fibrocytes and radial glia cells/astrocytes (s. 9). Pericytes of the CNS subventricular plexus transdifferentiate into radial astroglia $(61,62)$. Also Nestin-, NG2- and GFAPpositive cells were described in the CNS $(63,64)$. As mentioned below, the presumption exists that the perivascular resident macrophages are also pericyte progeny (65).

\section{Pericytes and Organ-blood and blood-tissue barriers}

It was also established that the pericytes are a key component of the different blood-tissue- and blood-organ barriers (blood-brain-, the blood-placenta-, the blood-retina-, the blood-testis- and the blood- thymus-barrier; 66, 67). 
The pericytes are also involved in the construction and function of the blood-labyrinth-barrier (BLB) of the inner ear (50) or cochlear intrastrial fluid-blood barrier (FBB; 2). The BLB comprises endothelial cells (ECs), pericytes (PCs), basement membrane (BM), perivascular resident macrophage-like melanocytes (PVM/Ms) and fibrocytes, which together form a complex "cochlear-vascular unit" in the strial microvasculature $(2,27,49,60$, 68 ). According to Shi (2) the BLB in the stria vascularis is a highly specialized capillary network that controls exchanges between the blood and the interstitial space in the cochlea. The BLB is important for the normal blood supply to the cochlea, for sustaining the endocochlear potential, ion transport, and endolymphatic fluid balance, and for preventing toxic substances from entering the cochlea (68). Moreover, it is important to note that the PVM/Ms possess typical astrocytic features thus, resembling astrocytes and glial cells of the central nervous system (CNS) blood brain barrier (BBB) $(27,46$; 59; see 69 for tissue resident perivascular macrophages which are also pericyte progeny). Recently, Zhelezov and Tonchev (65) discuss the possibility that ancestors of the monocyte-macrophage system may be the pericyte progenitors and the pericytes itself.

\section{Origin of the inner ear pericytes}

During early embryogenesis the epiblast (primitive ectoderm) represents a temporary structure. However, after its relatively fast exhaustion, the migrating epiblast progeny retain its pluripotency for a longer time until reaching the stage of specific cell differentiation (s. 70). At the same time these cells are involved in vasculogenesis and angiogenesis and partly become enclosed within the true microvascular niches where they remain the whole life as resting pluripotent adult stem cells (pericytes) for generation, repair and regeneration of outworn or damaged mature cell/tissue/organ structures of the vertebrate organisms.

The literature provides a lot of evidences indicating that the pericytes originate from the pluripotent embryonal epiblast. The epiblast (EPI) or primitive ectoderm represents part of a cell cluster (inner cell mass: ICM) at the animal (embryonic or implantation) pole of the embryonal blastocyst (71). Suwinska and Ciemerych (23) described that cells located deeper within the inner cell mass (ICM) form pluripotent EPI in postimplantation embryos (E5.5-E7.5 in the mouse) which generates the conceptus and some of the extraembryonic membranes, such as allantois and amnion. Epiblast cells migrate along the outer edges of the extraembryonic reticulum (which represents extracellular matrix produced by cytotrophoblast cells and cells of the Heuser's membrane) and form the extraembryonic mesoderm. From the anterior mesoderm a lateral region (the para-aortic splanchnopleura) the aorta-gonad-mesonephros (AGM) region arises $(39,40)$. The epiblast is the ancestor of the Primordial germ cells (PGCs) and hematopoietic stem cells (HSCs), which migrate from the hindgut and the yolk sac toward the AGM region at $10.5 \mathrm{dpc}$ in mice and around the 5th to 6th week in humans, and arrive into the genital ridges that lie on the dorsal body wall (11.5 dpc in mice and the 6th week in humans).

In addition to the PGCs and the HSCs the pluripotent EPI produces early the pericyte progenitors (cf. 9, 19, 39) and a little bit later the three embryonal germ cell-layers: ectoderm, mesoderm and endoderm (Fig. 1). The stem cell potential in the early embryo appears to depend on the interaction between the intrinsic (epigenetic) expressed embryonic and the appropriate extrinsic environmental factors for their cell fate determination (see also 22).The pericyte progenitors disseminate with the developing vasculature to the target structures and become pericytes situated within true niches of the microvasculature. It seems also very likely that these pluripotent cells become the ancestors of the structural components of the inner ear.

\section{Pericytes and the origin/regeneration of the inner ear structures}

It is well known that the structural components of the inner ear originate from an ectodermal thickening called otic placode (71). In higher vertebrate embryos, around the time of gastrulation, shortly after the origin of the neural plate, cells from the pregastrulation stage epiblast generate the neural crest and all placodes (72 - 75). As Chen and Streit (76) described, the placode specification is a multistep process. As a first step, in the ectoderm surrounding the anterior neural plate, a territory (band of ectoderm; neural plate border; NPB), designated pre-placodal region (PPR) differentiates (76 - 79, 121- 123) in which all sensory progenitor cells become specified (Fig. 1). Thus, the PPR constitutes a panplacodal primordium that produces 


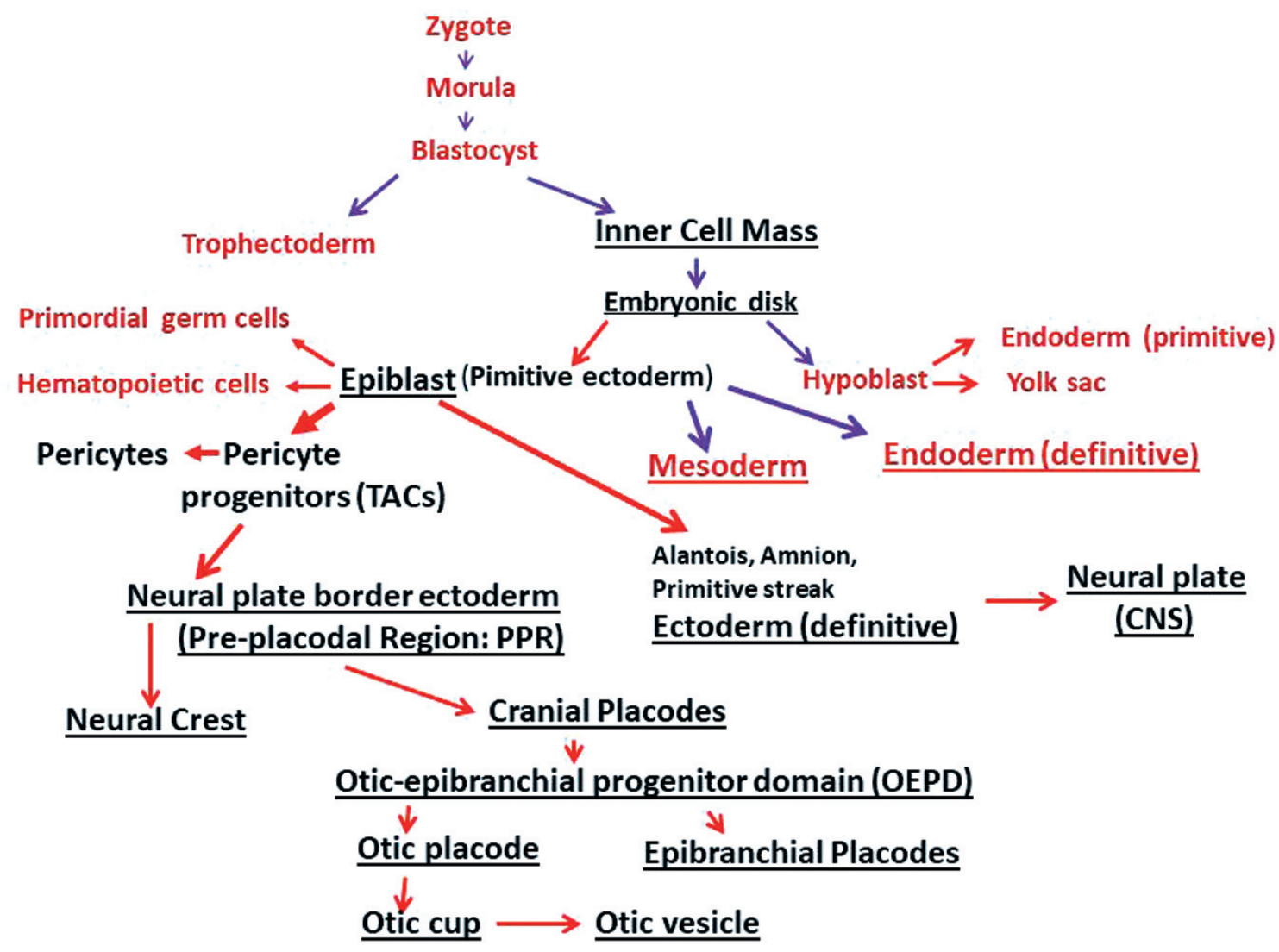

Figure 1: The diagram shows the initial phases of development of a vertebrate embryo from zygote to cranial placodes. Note, the epiblast (primitive ectoderm) produce pluripotent transit amplifying cells (TACs) which develop to pericyte progenitors and the Neural plate border ectoderm with the pre-placodal region (PPR) which further differentiate toward neural crest stem cells and the cranial placodes.

both, neural crest and placodes from populations of multipotent sensory progenitor cells near the border of the neural plate induced by signals of the neural plate (Hensen's node of the primitive streak /Spemann organizer/, "the organizer": 80) and the head mesoderm $(72,75)$, respectively. The pre-placodal region is in fact part of the pluripotent epiblast (s. 81, 120). In a second step follows the differentiation of the otic-epibranchial progenitor domain (OEPD) which represents a common territory for both otic and epibranchial precursor cells ("posterior placodal area", 73) which express Pax2 as one of the earliest OEPD markers $(76,79)$. In a third step the separate otic territory is formed (76) which is further converted into the invaginations: otic cup and otic vesicle.

The neural plate border pre-placodal ectoderm (NPB-PPE) cells express the transcription factor Six1 and its coactivator Eyal (74, 76, 82, 83). According Grocott et al (79) the Six and Eya network lies at the heart of sensory progenitor specification. It is important to note that the authors hypothesize that in response to neural and placode inducing signals, cells of the border pass through a common, preneural state, which is similar to the epiblast before gastrulation and to the embryonic stem cells (75). This fact provides evidence for the existence of pluripotent stem cells during a longer period of embryogenesis. This view is supported by the results of $\mathrm{Xu}$ et al (84), who reported, that a new established multipotent stem/progenitor cell population contribute to generation of hair, supporting and glial cells in the cochlea during development, maturation and repair. These multipotent progenitors originate from Eya1- expressing otic progenitors and its expression is later restricted to the sensory cells, the spiral ganglion cells with glial morphology and cells of the stria vascularis. Probably these cells are pericyte progeny in form of TPCs. In the spiral ganglion region the Eya1 positive cells express also Nestin, GFAP, Neurog1 and Neurod 1 (see 82, 85, 86). Xu et al (84) provide evidence that sensory hair cells and supporting cells in the organ of Corti as well as glial cells in 
their associated spiral nerve fibers and ganglion share a common progenitor. However, Hoijman et al (87) identify pioneer cells expressing Neurog1 outside the otic epithelium that migrate and ingress into the epithelializing placode to become the first otic neuronal progenitors. The authors emphasize that in the neurogenic domain, Neurog1 induces Neurod1 expression, which among others is required for delamination of neuroblasts from the epithelium. It seems very probable that these early ectoderm cells belong to the initial progeny (intermediate) of the epiblast cells being under way to generate the late ectoderm, the neural crest and the sensory placodes. The hypothesis for neural crest cell determination for production of inner ear cells was recently contradicted by a number of studies providing strong evidence that the neural crest stem cells do not contribute to creation of inner ear cells (see 86 for review).

In addition, Pechriggl et al (88) found that during the 8 gestation week (W8) in humans, Ki67+ cells coexpresing Nestin were seen in the epithelium of the future organ of Corti, especially in the lateral wall, in the greater epithelial ridge (GER) and the surrounding mesenchyme. At W11, Ki67 positive cells dramatically declined and were further differentiated to tympanic border cells and some supporting cells as shown by (89) in murine cochleae. Using Ki67 and bromo-deoxyuridine (BrdU) Taniguchi et al (89) describe in details the proliferative behavior of the Nestin positive tympanic border cells and their further differentiation toward sensory epithelial cells. In addition, the chick preplacodal epiblast express the transcription factor Spalt4 (also known as Sall4) that was later established in the otic, lens and olfactory placodes $(81,90)$. The authors presume that the Spalt4 may be involved in the creation of the placode region, because it is expressed earlier than the specific otic placode markers. Sall4 is also important for the delamination of neural cells from the placode ectoderm.

Presently, beside vasculature, there is no evidence for the direct participation of the pericytes in the generation and regeneration of cochlear cells. Currently it is favorited that the structural components of the inner ear originate and regenerate only from pluripotent stem cells (47, 91 - 93). Moreover, studies of the lateral line sensory epithelia in amphibians suggest that supporting cells, by a process of proliferation and transdifferentiation, may be the precursor for new hair cells following injury (94 - 96). In analogy with other mammalian tissues and organs, we presume that the ancestors of the cochlear structures are the pluripotent pericyte progenitors (as epiblast progeny) and the pericytes itself (representing the epiblast in the mature/adult organisms; see 9). Evidence for this hypothesis provide results obtained from studies on the embryonal and postnatal ear development as well as from studies that track the regeneration of the cochlear structures after their pathological and experimental destruction (97).

This interpretation is facilitated by recent evidences concerning the formation of the pluripotent epiblast in the preimplantation and postimplantation blastocyst during early embryogenesis $(22,23)$. According Trevers et al (75) cells from the pregastrulation stage epiblast generate the "pre-border" (structure between the primitive ectoderm (the epiblast) and the neural plate from which the sensory placodes arise) whose cells show similarity with the inducing factors producing cells of the Hensen's node, the head mesoderm and the hypoblast. The authors provide evidence that in response to neural and placode inducing signals, cells pass through a common preneural state, which resemble the epiblast before gastrulation. As mentioned, we suppose that the migrating epiblast progeny retain its pluripotency for a longer time before starting the specific differentiation. However, one part of these pluripotent stem cells become enclosed within the true microvascular niches and remain there in form of resting pluripotent adult stem cells the whole life for cell/tissue/organ generation and physiological and pathological reparation and regeneration (98, 99). Thus, it could not be excluded that these cells are the ancestors of the multipotent stem/progenitor cells described by Xu et al (84) that are progeny of the Eyal-expressing otic progenitors which can be established in the mouse postnatal cochlea beyond 1 week of age (s. 117).

One additional argument provides the differentiation of the basilar membrane vessel. It is most strongly activated during the embryonic development of the organ of Corti. After that it becomes inactivated and in some places it cannot be recognized $(28,48)$. This indicates that the vessel and its communicating branches are most active during the origin of the sensory cochlear structures (100) and after reaching the necessary number their production stops or diminishes significantly (84). Similarly, the vascular spiral plexus is most strongly 
activated during embryogenesis (88) and during the regeneration of the structures of the organ of Corti. Shi (49) provides a detailed description of the behavior of the cochlear pericytes following acoustic stress (wide-band noise exposure accompanied by hypoxia, vessel destruction, increase in pericyte coverage of the vessels, increased expression levels of desmin associated with the induction of hypoxia inducible factor (HIF)-1 $\alpha$ and the up-regulation of vascular endothelial growth factor (VEGF)). Shi (49) provides evidence that noise damages the blood-labyrinth barrier and induces vascular leakage. As a result the mechanosensory receptors (the inner ear hair cells) of the Corti organ are damaged or destructed and in mammals they are not able to regenerate. It seems likely that these cells are pericyte progeny that in form of TPCs move along the basilar membrane vessel and accumulate in this space as tympanic border cells. In the avian cochlea these cells further migrate upward, penetrate the basilar membrane and contribute for the regeneration of the cochlear supporting and hair cells as well as for neurons and glia cells of the spiral ganglion (89).

Thus, the supporting cells can be determined as TPCs of the pericytes that migrate (101) and differentiate to precursors of the supporting cells (cuboidal or hyaline epithelial: 97), Deiter's cells that resemble the CNS astrocytes or phalangeal cells (102), Hensen's cells (103) and finally the hair cells. The pericyte migration was associated with increased expression of platelet-derived growth factor beta (PDGF-BB; 101). Thus, these different cell types illustrate the differentiation pathway of the inner ear cells both during development and regeneration (104). A part of these multipotent precursors are responsible for the regeneration of the neurons and glial cells of the spiral ganglion. The behavior of otic pericytes (e.g. under hypoxic conditions) is identical in comparison with the CNS and other organ pericytes $(4,56,65,105)$. This concerns also the biochemical factors produced by these mural cells as well by some perivascular multipotent stromal mesodermal cells which are progeny of the pluripotent pericytes.

In this respect, there is strong evidence that healthy auditory hair cells in mammals inhibit the proliferation of the supporting cells possibly by the Notch signaling pathway (106 - 108). After acoustic trauma in chicken, injured hair cells secrete factors that inhibit the Notch pathway and induce the prolif- eration of the resting supporting cells to contribute for the regeneration of the Corti organ structures, inclusive the hair cells (s. 70, $109-112$ ). Rat and zebrafish hair cell regeneration was also achieved by Retinoic acid enhancement following repression of p27kip and Sox2 in the supporting cells (106, 111). SOX2 was established in pericyte precursors by (113). However these results do not explain the lack of hair cell regeneration in mammals because no new hair cells originate to inhibit the proliferation and the transdifferentiation (119) of the precursor cells. Thus, the discovery of the structures that release the inhibiting factors is awaited (119). In general, the process of regeneration of the inner ear cells resemble the events observed during the regeneration of destroyed Leydig cells of the rat testis $(4,5)$. The extensive proliferation of the precursor's stops after the necessary amount of new Leydig cells is achieved. Similarly, in the CNS, about 3 days after transient ischemia/reperfusion, within the injured areas, PDGFR- $Я$ positive perivascular pericytes start to express Nestin and differentiate further toward neural structures inhibiting the Nestin expression (105).

\section{Concluding remarks}

The results obtained in the studies about the embryogenesis provide a lot of evidences which allow the proposal of the hypothesis that the pericyte progenitors and the pericytes are the ancestors of the inner ear sensory epithelium. First of all, the fact that the development of different cells during the very early stages of the embryo (pregastrular, postgastrular, perineural border, preimplantation and postimplantation, preplacodal and placodal, pre-otic and otic state, creation of pluripotent stem cells; s. 114) as well as the very early development of the cardio-vascular system with primitive endothelial and hemopoetic/hematopoietic stem/ progenitor cells, leads to the important conclusion that all primary (primitive) structures possess pluripotent and multipotent capabilities and resemble the embryonal stem cells. Meanwhile, the leading position takes on the epiblast with his pluripotent stem cells which become distributed within the whole mammalian organism and in the adult ones remain as pericytes filed within the true microvascular niches.

Concerning the inner ear and the organ of Corti (OC) the following supporting results are important: 1. The early development of the vascular 
network, especially in the region of the lateral wall and the lateral (inferior) edge of the OC (115). This regional vasculature contains the most tight pericyte coverage. 2 . The origin of the pericyte progenitors and the pericytes from the pluripotent epiblast. 3. There are the capillary networks of the stria vascularis and the pericytes that become damaged by different reasons (acoustic trauma/loud sound, chemical intoxications etc.) which leads to hypoxia and degeneration of the hair cells. 4 . These changes activate the pericytes in the microvascular niches. 5. As adult stem cells the pericytes proliferate, migrate and contribute to the regeneration of the vasculature and the blood-labyrinth barrier. 6 . The pericyte descendants migrate as TACs that use as scaffold the basement membrane and the vessels under the organ of Corti, and differentiate toward tympanic border cells. 7. The tympanic border cells move upward and give rise to supporting cells, hair cells (in mammals their differentiation is inhibited) and neural and glial cells for the spiral ganglion. 8 . The similarity between the normal embryogenesis and the regeneration of the sensory epithelia of the inner ear concerning their fast proliferation and expression of characteristic factors, and the transition toward the resting state (118).

The established differences in the behavior of the pericytes in the different locations of the inner ear reflect their strong plasticity demonstrated by the situation of their differentiation state and the particularities of the local environment (120). For the future it will be very important to find possibility for preventing the inhibition of the hair cell regeneration in mammals' incl. human (s.108, 116, 125).

\section{References}

1. Bergers G, Song S. The role of pericytes in blood-vessel formation and maintenance. Neuro-Oncology 2005; 7(4):452-464. doi: 10.1215/ S1152851705000232

2. Shi X. Pathophysiology of the cochlear intrastrial fluid-blood barrier (review). Hear Res 2016; 338: 52-63. doi: 10.1016/ j.heares.2016.01.010

3. Hirschi KK, D’Amore PA. Pericytes in the microvasculature. Cardiovasc Res 1996; 32(4): 687-698. doi: 10.1016/S0008-6363(96)00063-6

4. Davidoff MS, Middendorff R, Enikolopov G, Rietmacher D, Holstein AF, Müller D. Progenitor cerlls of the testosterone-producing Leydig cells revealed. J Cell Biol 2004; 167: 935-944. doi:10.1083/jcb.2004091

5. Davidoff MS, Middendorff R, Müller D, Holstein AF. The neuroendocrine Leydig cells and their stem cell progenitors, the pericytes. Advances in Anatomy, Embryology and Cell Biology, Springer 2009; 205: 1-154. doi: 10.1007/978-3-642-00513-8

6. Friedrich R, Holstein AF, Middendorff R, Davidoff MS. Vascular wall cells contribute to tumourigenesis in cutaneous neurofibromas of patients with neurofibromatosis type 1. A comparative histological, ultrastructural and immunohistochemical study. Anticancer Res 2012; 32(5): 2139-2158

7. Kloc M, Kubiak JZ, Li XC, Ghobrial RM. Pericytes, microvascular dysfunction, and chronic rejection. Transplantation 2015; 99(4): 658667. doi: 10.1097/TP.0000000000000648

8. Davidoff MS. The Leydig cells of the testis originate from the microvascular pericytes. Biomedical Reviews 2017; 28: 5-25. doi: 10.14748/ bmr.v28.4448

9. Davidoff MS. The pluripotent microvascular pericytes are the adult stem cells even in the testis. In: A Birbarir (ed), Capter 13, Pericyte Biology in Different Organs, Springer Nature Switzerland AG, Adv Exp Med Biol 2019; 1122: 235-268. doi: 10.1007/978-3-030-11093-2 13

10. Gerhardt H, Betsholtz C. Endothelial-pericyte interactions in angiogenesis. Cell Tissue Res 2003; 314 (1):15-23. doi: 10.1007/s00441-0030745-x

11. Diaz-Flores L, Gutiérrez R, Madrid JF. et al. Pericytes. Morphofunction, interactions and pathology in a quiescent and activated mesenchymal cell niche. Histol Histopathol 2009; 24(7): 909- 969. doi: 10.14670/HH-24.909

12. Crisan M, Yap S, Casteilla L. et al. A perivascular origin for mesenchymal stem cells in multiple human organs. Cell Stem Cell 2008; 3(3): 301-313. doi: 10.1016/J.Stem.2008.07.003

13. Crisan M, Corselli M, Chen C-W, Péault B. Multilineage stem cells in the adult. A perivascular legacy? Organogenesis 2011; 7(2): 101-104. doi: 10.4161/org.7.2.16150

14. Bouacida A, Rosset P, Trichet V. et al. Pericyte-like progenitors show high immaturity and engraftment potential as compared with mesenchymal stem cells. PLoS ONE 2012; 7(11): e486548. doi: 10.137/journal.pone.0048648

15. Stapor PC, Sweat RS, Dashti DC, Betancourt AM, Murfee WL. Pericyte dynamics during angiogenesis: new insights from new identities. J Vasc Res 2014; 51(3): 163-174. doi:10.1159/000362276

16. Chen J, Luo Y, Hui H. et al. CD146 coordinates brain endothelial cell - pericyte communication for Blood - brain barrier development. Proc Natl Acad Sci USA 2017; 114(36): E7622-E7631. doi: 10.1073/pnas.1710848114

17. Guimarães-Camboa N, Cattaneo P, Sun Y. et al. Pericytes of multiple organs do not behave as mesenchymal stem cells in vivo. Cell Stem Cell 2017; 20(3): 345-359. doi: 10.1016/j.stem.2016.12.006

18. Cano E, Gebala V, Gerhardt H. Pericytes or mesenchy $\neg$ mal stem cells: Is that the question? Cell Stem Cell 2017; 20(3): 296-297. doi: 10.1016/j.stem.2017.02.005

19. Montiel-Eulefi E, Sánchez R, Rojas M, Bustos-Obregon E. Epiblast embryo stem cells give origin to adult pluripotent cell populations: primordial germ cell, pericytic and haematopoietic stem cells. A review. Int J Morphol 2009; 27(4): 1325-1333. doi: 10.4067/S071795022009000400056

20. Montiel-Eulefi E, Nery AA, Rodrigues LC, Sánchez R, Romero F, Ulrich H. Neural differentiation of rat aorta pericyte cells. Cytometry 2012; Part A 81A: 65-71. doi:10.1002/cyto.a.21152

21. Péault B, Rudnicki M, Torrente Y. et al. Stem and progenitor cells in skeletal muscle development, maintenance, and therapy. Mol Ther 2007; 15(5): 867- 877. doi: 10.1038/mt.sj.6300145 
22. Rossant J. Stem cells from the mammalian blastocyst. Stem Cells 2001; 19(6): 477-482. doi: 10.1634/stemcells.19-6-477

23. Suwinska A, Ciemerych MA. Factors regulating pluripotency and differentiation in early mammalian embryos and embryo-derived stem cells. In: Gerald Litwack (Ed) Stem Cell Regulators, Vitam Horm 2011; 87: 1-37. doi: 10.1016/B978-0-12-386015-6.00022-6

24. Bianco P, Robey PG. Skeletal stem cells. Development 2015; 142(6): 1023-1027. doi: 10.1242/dev.102210.

25. Caplan AI. All MSCs are pericytes? Cell Stem Cell 2008; 3(3):229-230. doi: 10.1016/J.Stem.2008.08.008

26. Zouani OF, Lei Y, Durrieu M-C. Pericytes, stem-cell-like cells, but not mesenchymal stem cells are recruited to support microvascular tube stabilization. Small 2013; 9(18): 3070-3075. doi: 10.1002/smll.201300124

27. Shi X. Physiopathology of the cochlear microcirculation. Hear Res 2011; 282(1-2): 10-24. doi:10.1016/j.heares.2011.08.006.

28. Hornstrand C, Axelsson A, Vertes D. The vascular anatomy of the rat cochlea, Acta Oto-Laryngologica 1980; 89(1-2): 1-11, doi: 10.3109/0 0016488009127102

29. Risau W, Flamme I. Vasculogenesis. Annu Rev Cell Dev Biol 1995; 11: 73-91. doi: 10.1146/annurev.cb.11.110195.000445

30. Flamme I, Frölich T, Risau W. Molecular mechanisms of vasculogenesis and embryonic angiogenesis. J Cell Physiol 1997; 173(2): 206-210. doi: 10.1002/(SICI)1097-4652(199711)173:2<206::AID-JCP22>3.0.CO;2- C

31. Udan RS, Culver JC, Dickinson ME. Understanding vascular development: Wiley Interdiscip Rev Dev Biol 2013; 2(3): 327-346. doi:10.1002/wdev.91

32. Drake CJ, Fleming PA. Vasculogenesis in the day 6.5 to 9.5 mouse embryo. Blood 2000; 95(5): 1671-1679.

33. Mitrani E, Gruenbaum Y, Shohat H, Ziv T. Fibroblast growth factor during mesoderm induction in the early chick embryo. Development 1990; 109(2): 387-393

34. Dyer LA, Patterson C. Development of the endothelium: An emphasis on heterogeneity. Semin Thromb Hemost 2010; 36(3): 227-235. doi:10.1055/s-0030-1253446

35. Risau W. Mechanisms of angiogenesis. Nature 1997; 386(6626): 671-674. doi: 10.1038/386671a0

36. Carmeliet P. Angiogenesis in life, disease and medicine. Nature 2005; 438(7070): 932-936. doi: 10.1038/nature04478

37. Godin I, Dieterlen-Lièvre F, Cumano A. Emergence of multipotent hemopoietic cells in the yolk sac and paraaortic splanchnopleura in mouse embryos, beginning at 8.5 days postcoitus. Proc Natl Acad Sci USA 1995; 92(3): 773-777. doi: 10.1073/pnas.92.3.773

38. Goldie LC, Nix MK, Hirschi KK. Embryonic vasculogenesis and hematopoietic specification. Organogenesis 2008; 4(4): 257-263. doi: 10.4161/org.4.4.7416

39. De-Miguel MP, Arnalich Montiel F, Lopez Iglesias P, Blazquez Martinez A Nistal M. Epiblast-derived stem cells in embryonic and adult tissues. Int J Dev Biol. 2009; 53(8-10):1529-1540. doi: 10.1387/ijdb.072413md.

40. De-Miguel MP, Fuentis-Julian S, Alcaina Y. Pluripotent stem cells: origin, maintenance and induction. Stem Cell Rev and Rep 2010; 6(4): 633-6409. doi: 10.1007/s12015-010-9170-1.

41. Taylor E, Taodi S, Medvinsky A. Hematopoietic stem cell activity in the aorta-gonad-mesonephros region enhances after mid-day 11 of mouse development. Int J Dev Biol 2010; 54(6-7): 1055-1060. doi: 10.1387/ijdb.103152et

42. Arora R, Papaioannou VE. The murine allantois: a model system for thestudy of blood vessel formation. Blood 2012; 120(13): $2562-2572$. doi: 10.1182 / blood-2012-03-390070

43. Cho H, Kozasa T , Bondjers C, Betsholtz C, Kehrl JH. Pericyte-specific expression of Rgs5: implications for PDGF and EDG receptor signaling during vascular maturation . FASEB J 2003; 17(5): 440-442. doi: 10.1096/fj.02-0340fje

44. Mei X, Atturo F, Wadin K. et al. Human inner ear blood supply revisited: the Uppsala collection of temporal bone - an international resource of education and collaboration. Upsala J Med Sci 2018; 123(3): 131-142. doi: 0.1080/03009734.2018.1492654

45. Shi X, Han W, Yamamoto H. The cochlear pericytes. Microcirculation 2008; 15(6): 515-529. doi: 10.1080/10739680802047445

46. Shi X. Cochlear pericyte responses to acoustic trauma and the involvement of hypoxia-inducible factor-1 $\alpha$ and vascular endothelial growth factor. Am J Pathol 2009; 174(5): 1692-1704. doi: 10.2353/ajpath.2009.080739

47. Chen W, Jongkamonwiwat N, Abbas L. et al. Restoration of auditory evoked responses by human ES cell-derived otic progenitors. Nature 2012; 490(7419): 278-282. doi:10.1038/nature11415

48. Jiang H, Wang X, Zhang J, Kachelmeier A, Lopez IA, Shi X. Microvascular networks in the area of the auditory peripheral nervoussystem. Hearing Research 2019; 371: 105-116. doi: 10.1016/j.heares.2018.11.012

49. Dai M, Shi X. Fibro-vascular coupling in the control of cochlear blood flow. PLoS ONE 2011; 6(6): e20652. doi:10.1371/journal. pone.0020652

50. Canis M, Bertlich M. Cochlear Capillary Pericytes, Chapter 7, A. Birbrair (ed.) Pericyte Biology in Different Organs, Advances in Experimental Medicine and Biology 1122, Springer Nature Switzerland AG 2019; doi: 10.1007/978-3-030-11093-2_7, pp 115-123

51. Oshima K, Grimm CM, Corrales CE. et al. Differential distribution of stem cells in the auditory and vestibular organs of the inner ear. JARO 2007; 8(1): 18-31. doi: 10.1007/s10162-006-0058-3

52. Axelsson A. Comparative anatomy of cochlear blood vessels. Am J Otolaryngol 1988; 9(6):278-290. doi; 10.1016/S0196-0709(88)80036$\mathrm{X}$

53. Montiel-Eulefi E, Sánchez R, Rojas M, Bustos-Obregon E. Epiblast embryo stem cells give origin to adult pluripotent cell populations: primordial germ cell, pericytic and haematopoietic stem cells. A review. Int J Morphol 2009; 27(4): 1325-1333. Doi: 10.4067/S071795022009000400056

54. Carmeliet P. Blood vessels and nerves: common signals, pathways and diseases. Nature Reviews 2003; 4(7048): 710-720. doi: 10.1038/ nature 03875

55. Sweeney MD, Ayyadurai S, Zlokovic BV. Pericytes of the neurovascular unit: key functions and signaling pathways. Nature Neurosci 2016; 19 (6): 16 771-16 783. doi:10.1038/nn.4288

56. Cai W, Liu H, Zhao J. et al. Pericytes in brain Injury and repair after ischemic stroke. Transl Stroke Res 2017; 8(2):107-121. doi: 10.1007/ s12975-016-0504-4

57. Stebbins MJ, Gastfriend BD, Canfield SG. et al. Human pluripotent stem cell-derived brain pericyte-like cells induce blood-brain barrier properties. Science Advances 2019; 5(3): eaau7375. doi: 10.1126/sciadv.aau7375

58. Dore-Duffy P. Pericytes: pluripotent cells of the blood brain barrier. Curr Pharm Des 2008; 14(16): 1581-1593. doi: 10.2174/13816120878 4705469

59. Sá-Pereira I, Brites D, Brito MA Neurovascular unit: a focus on pericytes. Mol Neurobiol 2012; 45(2): 327-347. doi: 10.1007/s12035-0128244-2

60. Zhang F, Dai M, Neng L. Perivascular macrophage-like melanocyte responsiveness to acoustic trauma - a salient feature of strial barrier associated hearing loss. FASEB J 2013; 27(9):3730-3740. doi:10.1096/fj.13- 232892 
61. Alvarez-Buylla A, Seri B, Doetsch F (2002) Identification of neural stem cells in the adult vertebrate brain. Brain Res Bull 57(6): 751-758. doi: 10.1016/S0361-9230(01)00770-5

62. Sild M, Rithazer ES (2011) Radial glía: progenitor, pathway, and partner. Neurosci 17(3) 288-302. doi: 10.1177/1073858410385870

63. Wei LC, Shi M, Chen LW, Cao R, Zhang P, Chan YS. Nestin-containing cells express glial fibrillary acidic protein in the proliferative regions of central nervous system of postnatal developing and adult mice. Brain Res Dev Brain Res 2002; 139(1): 9-17. doi: 10.1016/s01653806(02)00509-6

64. Zhu X, Bergles DE, Nishiyama A. NG2 cells generate both oligodendrogcytes and gray matter astrocytes. Development 2008; 135(1): 145157. doi: $10.1242 /$ dev.004895

65. Zhelezov M, Tonchev AB. Microglia are not brain macrophages? Biomedical Reviews 2018; 29: 99-108

66. Fröhlich E. Aufbau und Funktion von Blut-Gewebe-Schranken (Structure and function of blood-tissue barriers). Dtsch med Wochenschr 2002; 127(49): 2629-2634. doi: 10.1055/s-2002-35932

67. Caceres PS, Benedicto I, Lehmann GL. Rodriguez-Boulan EJ. Directional fluid transport across organ-blood barriers: physiology and cell biology. Cold Spring Harb Perspect Biol 2017; 9(3): a027847. doi: 10.1101/cshperspect.a027847

68. Suko T, Ichimiya I, Yoshida K, Suzuki M, Mogi G. Classification and culture of spiral ligament fibrocytes from mice. Hearing Research 2000; 140(1-2): 137-144. doi: 10.1016/S0378-5955(99)00191-4

69. He H, Mack JJ, Güç E. et al. Perivascular macrophages limit permeability. Arterioscler Thromb Vasc Biol 2016; 36(11): 2203-2212. doi: 10.1161/ATVBAHA.116.307592

70. Bramhall NF, Shi F, Arnold K, Hochedlinger K, Edge ASB. Lgr5- positive supporting cells generate new hair cells in the postnatal cochlea. Stem Cell Reports 2014; 2(3): 311-322. doi: 10.1016/j.stemcr.2014.01.008

71. Streit A. Early development of the cranial sensory nervous system: from a common field to individual placodes. Dev Biol 2004; 276(1): 1- 15. doi: 10.1016/j.ydbio.2004.08.037

72. Schlosser G. Induction and specification of cranial placodes. Dev Biol 2006; 294(2): 303-351. doi:10.1016/j.ydbio.2006.03.009

73. Ladher RK, O’Neill P, Begbie J. From shared lineage to distinct functions: the development of the inner ear and epibranchial placodes. Development 2010; 137(11): 1777-1785. doi:10.1242/dev.040055

74. Maharana SK, Schlosser G. A gene regulatory network underlying the formation of pre-placodal ectoderm in Xenopus laevis. BMC Biology 2018; 16(1):79. doi: 10.1186/s12915-0 18-0540-5

75. Trevers KE, Prajapati RS, Hintze M. et al. Neural induction by the node and placode induction by head mesoderm share an initial state resembling neural plate border and ES cells. Proc Natl Acad Sci USA 2018; 115(2): 355-360. doi:10.1073/pnas.1719674115

76. Chen J, Streit A. Induction of the inner ear: stepwise specification of otic fate from multipotent progenitors. Hear Res 2013; 297: 3-12. doi: 10.1016/j.heares.2012.11.018

77. Jacobson AG. Inductive processes in embryonic development. Science 1966; 125(3718): 25- 34. doi: 10.1126/science.152.3718.25

78. Streit A. Early development of the cranial sensory nervous system: from a common field to individual placodes. Dev Biol 2004; 276(1): 1- 15. doi: 10.1016/j.ydbio.2004.08.037

79. Grocott T, Tambalo M, Streit A. The peripheral sensory nervous system in the vertebrate head: A gene regulatory perspective. Dev Biol 2012; 370(1): 3-23. doi: 10.1016/j.ydbio.2012.06.028

80. Streit A, Berliner AJ, Papanayotou C, Sirulnik A, Stern CD (2000) Initiation of neural induction by FGF signalling before gastrulation. Nature 2000; 406(6791): 74-78. doi: 10.1038/35017617

81. Barembaum M, Bronner-Fraser M. Spalt4 mediates invagination and otic placode gene expression in cranial ectoderm. Development 2007; 134(21): 3805-3814. doi:10.1242/dev.02885

82. Kalatzis V, Sahly I, El-Amraoui A, Petit C. Eya1 expression in the developing ear and kidney: towards the understanding of the pathogenesis of Branchio-Oto-Renal (BOR) syndrome. Dev Dyn 1998; 213(4):486-499. doi: 10.1002/(SICI)1097-0177(199812)213:4<486::AIDAJA13>3.0.CO;2-L

83. Xu PX, Adams J, Peters H. et al. Eya1- deficient mice lack ears and kidneys and show abnormal apoptosis of organ primordia. Nat. Genet.1999; 23(1): 113-117. doi: 10.1038/12722

84. Xu J, Ueno H, Xu CY. Et al. Identification of mouse cochlear progenitors that develop hair and supporting cells in the organ of Corti. Nature Comm 2017; 8:15046 . doi: 10.1038/ncomms15046

85. Ahmed M, Xu J, Xu PX. EYA1 and SIX1 drive the neuronal developmental program in cooperation with the SWI/SNF chromatin-remodeling complex and SOX2 in the mammalian inner ear. Development 2012; 139(11): 1965-1977. doi: 10.1242/dev.071670

86. Fritzsch B, Pan N, Jahan I, Elliott KL. Inner ear development: building a spiral ganglion and an organ of Corti out of unspecified ectoderm. Cell Tissue Res 2015; 361(1): 7-24. doi: 10.1007/s00441-014-2031-5.

87. Hoijman E, Fargas L, Blader P, Alsina B. Pioneer Neurog1 expressing cells ingress into the otic epithelium and instruct neuronal specification. eLife 2017; 6: e25543. doi: 10.7554/eLife.25543

88. Pechriggl EJ, Bitsche M, Glueckert R. et al. Development of the innervation of the human inner ear. Dev Neurobiol 2015; 75(7): 683-702. doi: $10.1002 /$ dneu.22242.

89. Taniguchi M, Yamamoto N, Nakagawa T, Ogino E, Ito J. Identification of tympanic border cells as slow-cycling cells in the cochlea. PLoS One 2012; 7(10): e48544. doi: 10.1371/journal.pone.0048544\#

90. de Celis JF, Barrio R. Regulation and function of Spalt proteins during animal development. Int J Dev Biol 2009; 53(8-10):1385-1398. doi: 10.1387/ijdb.072408jd

91. Oshima K, Shin K, Diensthuber M, Peng AW, Ricci AJ, Heller S. Mechanosensitive hair cell-like cells from embryonic and induced pluripotent stem cells. Cell 2010; 141(4): 704-716. doi:10.1016/j.cell.2010.03.035.

92. Koehler KR, Mikosz AM, Molosh AI, Patel D, Hashino E. Generation of Inner ear sensory epithelia from pluripotent stem cells in 3D culture. Nature 2013; 500(7461): 217-221. doi: 10.1038/nature12298

93. Jeong M, O'Reilly M, Kirkwood NK. et al. Generating inner ear organoids containing putative cochlear hair cells from human pluripotent stem cells. Cell Death Disease 2018; 9 (9): 922. doi: 10.1038/s41419-018-0967-1

94. Corwin JT. Postembryonic production and aging of inner ear hair cells in sharks. J Compar Neurol 1981; 201(4): 541-553. doi:10.1002/ cne.902010406

95. Corwin JT. Regeneration in the auditory system. Exp Neurol 1992; 115(1): 7-12. doi: 10.1016/0014-4886(92)90212-9

96. Corwin JT, Cotanche DA. Regeneration of sensory hair cells after acoustic trauma. Science 1988; 240(4860): 1772-1774. doi: 10.1126/science. 3381100 
97. Girod DA, Duckert LG, Rubel EW. Possible precursors of regenerated hair cells in the avian cochlea following acoustic trauma. Hear Res 1989; 42: 175-194

98. da Silva Meirelles L, Caplan AI, Nardi NB. In search of the in vivo identity of mesenchymal stem cells. Stem Cells 2008; 26(9): $2287-2299$. doi: 10.1634/stemcells.2007-1122

99. da Silva Meirelles L, Caplan A I, Nardi NB. Pericytes as the source of mesenchymal stem cells. Chapter 12. In: Resident Stem Cells and Regenerative Therapy. Elsevier Inc. 2013: 233-250. doi: 10.1016/B978-0-12-416012- 5.00012-8

100. Iwagaki T, Suzuki T, Nakashima T. Development and regression of cochlear blood vessels in fetal and newborn mice. Hearing Research 2000; 145(1- 2): 75-81. doi: 10.1016/S0378-5955(00)00075-7

101. Hou Z, Wang X, Cai J. et al. Platelet- derived growth factor subunit B signaling promotes pericyte migration in response to loud sound in the cochlear stria vascularis. J Assoc Res Otolaryngol 2018; 19(4):363-379. doi: 10.1007/s10162-018-0670-z.

102. Yamasoba T, Kondo K. Supporting cell proliferation after hair cell injury in mature guinea pig cochlea in vivo. Cell Tissue Res 2006; 325(1): 23-31. Doi: 10.1007/s00441-006-0157-9

103. Malgrange B, Thiry M, Van de Water TR, Nguyen L, Moonen G, Lefebvre PP. Epithelial supporting cells can differentiate into outer hair cells and Deiters' cells in the cultured organ of Corti. Cell Mol Life Sci 2002; 59(10); 1744-1757. doi: 10.1007/PL00012502

104. Wan G, Corfas G, Stone JS. Inner ear supporting cells: Rethinking the silent majority. Semin Cell Dev Biol 2013; 24(5): 448-459. doi:10.1016/j.semcdb.2013.03.009.

105. Nakata M, Nakagomi T, Maeda M, Nakano-Doi A, Momota Y, Matsuyama T. Induction of perivascular neural stem cells and possible contribution to neurogenesis tollowing transient brain ischemia/reperfusion injury. Translational stroke research. 2017; 8(2): 131-143. doi: 10.1007/s12975-016- 0479-1.

106. Lefebvre PP, Malgrange B, Staecker H, Moonen G, Van de Water TR. Retinoic acid stimulates regeneration of mammalian auditory hair cells. Science 1993; 260(5108): 692-695. doi: 10.1126/science.8480180

107. McGovern MM, Zhou L, Randle MR, Cox BC. Spontaneous hair cell regeneration is prevented by increased Notch signaling in supporting cells. Front Cell Neurosci 2018; 12:120. doi: 10.3389/fncel.2018.00120

108. Youm I, Li W. Cochlear hair cell regeneration: an emerging opportunity to cure noise-induced sensorineural hearing loss. Drug Discov Today 2018; 23(8):1564-1569. doi: 10.1016/j.drudis.2018.05.001.

109. Lanford PJ, Lan Y, Jiang R. et al. Notch signalling pathway mediates hair cell development in mammalian cochlea. Nature Genet 1999; 21(3): 289-292. doi: 10.1038/6804

110. Wu DK, Kelley MW (2012) Molecular mechanisms of inner ear development. Cold Spring Harb Perspect Biol 4(8): a008409. doi: 10.1101/ cshperspect.a008409

111. Rubbini D, Robert-Moreno A, Hoijman E, Alsina B. Retinoic acid signaling mediates hair cell regeneration by repressing p27kip and Sox2 in supporting cells. J Neurosc 2015; 35 (47):15752-15766. doi: 10.1523/JNEUROSCI. 1099.2015.

112. Franco B, Malgrange B. Concise review: Regeneration in mammalian cochlea hair cells: Help from supporting cells transdifferentiation. Stem Cells 2017; 35(3):551-556. doi: 10.1002/stem.2554

113. Kälin R, Li Y, Linzhi C. et al. CBMT-40. A SOX2-expressing pericyte precursor constitutes a new and efficient target for anti-angiogenesis in gliomas. Neuro-Oncology 2018; 20 (suppl_6): vi41. doi: 10.1093/neuonc/noy148.159

114. Abelló G, Khatri S, Radosevic M, Scotting PJ, Giráldez F, Alsina B. Independent regulation of Sox3 and Lmx1b by FGF and BMP signaling influences the neurogenic and non-neurogenic domains in the chick otic placode. Devel Biol 2010; 339(1): 166-178. doi:10.1016/ j.ydbio.2009.12.027I

115. Waqas M, Gao S, Iram-us-Salam, Ali MK, Ma Y, Li W. Inner ear hair cell protection in mammals against the noise-induced cochlear damage. Neural Plasticity 2018; 2018: 3170801. doi:10.1155/2018/3170801

116. $\mathrm{Hu}$ N, Rutherford MA, Green SH. Protection of cochlear synapses from noise-induced excitotoxic trauma by blockade of Ca2+-permeable AMPA receptors. Proc Natl Acad Sci USA 2020; 117(7): 3828-3838. doi/10.1073/pnas.1914247117

117. Liu JA, Tai A, Hong J. et al. Fbxo9 functions downstream of Sox10 to determine neuron-glial fate choice in the dorsal root ganglia through Neurog2 destabilization. Proc Natl Acad Sci USA 2020; 117(8): 4199-4210. doi: 10.1073/pnas.1916164117

118. Levic S, Nie L, Tuteja D, Harvey M, Sokolowski BHA, Yamoah EN. Development and regeneration of hair cells share common functional features. Proc Natl Acad Sci USA 2007; 104(48): 9108-19113. doi: 10.1073 pnas.0705927104

119. Defourny J, Sánchez SM, Schoonaert L. et al. Cochlear supporting cell transdifferentiation and integration into hair cell layers by inhibition of ephrin-B2 signalling. Nature Commun 2015; 6:7017. doi: 10.1038/ncomms8017

120. Reichert S, Randall RA, Hill CS. A BMP regulatory network controls ectodermal cell fate decisions at the neural plate border. Development 2013; 140(21): 4435-4444. doi: 10.1242/dev.098707

121. Saint-Jeannet J-P, Moody SA. Establishing the pre-placodal region and breaking it into placodes with distinct identities. Dev Biol 2014; 389(1): 13-27. doi:10.1016/j.ydbio.2014.02.011.

122. Schille C, Schambony A. Signaling pathways and tissue interactions in neural plate border formation. NEUROGENESIS 2017; 4(1): e1292783 (12 pages). doi: 10.1080/23262133.2017.1292783

123. Bronner ME and Simões-Costa M. The neural crest migrating into the 21st century. Curr Top Dev Biol 2016; 116: 115-134 doi:10.1016/ bs.ctdb.2015.12.003

124. Baker SG. The detached pericyte hypothesis: A novel explanation for many puzzling aspects of tumorigenesis. Organisms J Biol Sci 2018; 2(1): 25- 41. DOI: $10.13133 / 2532-587633.10$.

125. Gnedeva K, Wang X, McGovern MM, Barton M, Tao L, Trecek T, Tanner O. Monroe TO, Llamas J, Makmura W, Martin JF, Groves AK, Warchol M, Segil N. Organ of Corti size is governed by Yap/Tead-mediated progenitor self-renewal. Proc Natl Acad Sci USA $2020 ; 117$ (24): 13552-13561. doi:10.1073/pnas.2000175117

\section{Correspondence:}

Prof. Dr. med. Michail S. Davidoff. University Medical Center Hamburg-Eppendorf,

Museum of Medical History, N30b, Martinistrasse 52,

D-20246 Hamburg, Germany.

Tel: +49 (0) 40 7410-54482;

E-mail:davidoff@uke.de 


\section{Curriculum}

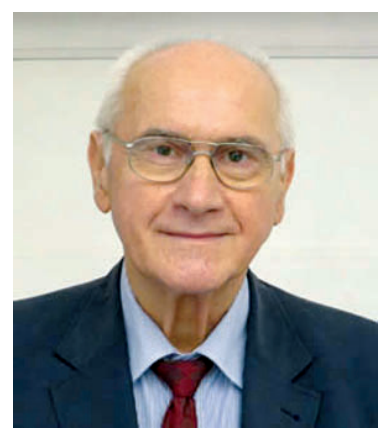

Prof. Michail S. Davidoff, MD, PhD, DrS, is full Member of the German Academy of Sciences "Leopoldina" (since 1985), Corresponding Member of the Bulgarian Academy of Sciences (since 1989) and Full University Professor in Anatomy of the Medical Faculty of the University of Hamburg, Germany.

In 1966 he finished his University education in human medicine at the Higher Medical Institute - Sofia/Bulgaria and became the degree doctor of medicine (MD). He started his professional activity as scientific research fellow at the Regeneration Research Laboratory of the Bulgarian Academy of Sciences-Sofia and simultaneously as Assistant at the Department of Human Anatomy as well as the Department of Histology and Embryology of the Higher Medical Institute-Sofia.

After successful defense (1971) of the first habilitation thesis („Electron microscopical characteristics and histochemistry of the developing and differentiated guinea pig placenta") he was habilitated and 1974 appointed to Associate professor for Anatomy, Histology and Embryology at the Regeneration Research Laboratory of the Bulgarian Academy of Sciences and simultaneously as Visiting Associate Professor at the Department of Anatomy, Histology and Embryology of the Higher Medical Institute of Pleven, Bulgaria.

In 1977 he defense his 2nd Habilitation Thesis („Lysosomes of the Central Nervous System“) and was appointed as Doctor of Medical Sciences (DrS).

In 1982 he became appointment to Professor of Anatomy, Histology and Embryology and Professor at the Regeneration Research Laboratory of the Bulgarian Academy of Sciences. During 1989 - 1994 he was elected as Professor and Vice Director at the Institute of Cell Biology and Morphology of the Bulgarian Academy of Sciences. Following appointment procedure professorship, in 1993 he was elected as Full University Professor and Vice director (2000 - 2001 Acting director) of the Institute of Anatomy of the University of Hamburg, Germany.

At the end of 2005 Davidoff got Retired professor at the Anatomical Institute of the University of Hamburg, Germany and continued his activity as Professor of Anatomy (teacher and scientist) according additional contract with the Medical Faculty (until 2010) and further volunteer work as member of the board of the Society: „Freundes- und Förderkreis des UKE-Hamburg“, Germany and of the Museum of Medical History of Hamburg.

Prof. Davidoff was multiple times Visiting Associate Professor and Professor at the institute of Anatomy, University of Würzburg and Visiting professor at the Institute of Anatomy, University of Hamburg, Germany Since 1969 he became a member of the Society for Histochemistry and 1972 Member of the Anatomical Society ("Anatomische Gesellschaft" of Germany

More than 10 years (1968-1991) he acted as Member of the board and as Secretary of the Bulgarian Society of Anatomy, Histology and Embryology. In addition, in the time 1982 - 1989 he was President of the Histochemical Section of the Bulgarian Society of Anatomy, Histology and Embryology. From 1989 to 1991 Davidoff was President of the Specialized Scientific Council on Morphology of the Higher Attestation Commission of Bulgaria. Between1998 and 2002 he was Member of the board and President (2001) of the "Anatomische Gesellschaft" - Germany.

In 1999 he was honored as an honorary member of the Bulgarian Anatomical Society and of the Romanian Society of Anatomy.

During the whole time of his professional life in Bulgaria and Germany Prof. Davidoff kept contact with the Bulgarian Institutions, students and colleagues and supported their work and careers. He was appreciated as a professor by his students and also enjoyed the friendship and respect of his colleagues. In 2005 he got the award "Teacher of the decade" in the pre-clinical medicine subjects of the Medical Faculty Hamburg/ Germany.

The Main topics of research of Prof. Davidoff are:

1. Morphology of the central and peripheral nervous system in norm and experiment.

2. Structure and function of different parenchymal Organs.

3. Morphology, function and origin of the neuroendocrine cell systems.

4. The Adult stem cells 